\title{
Service Orchestration on the Internet of Things
}

\author{
Jordán Pascual Espada \\ Computer Sciencie Department, University of Oviedo, Oviedo, Spain
}

\begin{abstract}
On July 27, 2010, Jordán Pascual Espada defended his Master's thesis at Oviedo University (Spain), titled: "Service Orchestration on the internet of things". This Master's thesis is the final part of the Web Engineering Official Research Master belonging to the European Higher Education Area. Jordán Pascual Espada defended his dissertation in a publicly open presentation held in the School of Computer Engineering at Oviedo University, and was able to comment on every question raised by his committee and the audience. The master's thesis was supervised by his advisors, Juan Manuel Cueva Lovelle and Oscar Sanjuán Martínez. The thesis has been read and approved by his thesis committee, receiving the highest rating
\end{abstract}

Keywords - Virtual Object, Internet of Things, DDTS, Web Services, Smart Phone.

\section{SUMMARY}

Tnternet of things promotes that many physical objects and Eelectronic devices are able to communicate with other similar autonomous. These physical objects must be clearly identified; in most cases they contain a digital part as a microprocessor or a radio frequency tag. Multitude of different physical objects can be part of the internet of things systems, appliances, vehicles, industrial machinery, services machines, etc. Internet of Things offers a new range of possibilities to make life easier for people supporting or automating many daily tasks.

Same time as technology advances more and more objects "things" that were only beginning to appear physically in digital format. Examples are: books, maps, event tickets, airline tickets, calendars, contact cards, electronic purses, etc.. By observing the behavior of these digital objects we find that there is no standard format or recommendations to standardize its use, no mechanism to deal with in a general way, store, share, or processing by other applications that are not familiar with the specific format.

Problems arising from the lack of standardization in digital objects are:

1. Most of the virtual objects have a specific format, these objects are composed of different types of files and structures. The software application that manages the virtual object should be able to decode it, to operate with it. This handicap leads to the need of installing many applications in case we want to operate with different virtual objects. It makes it harder for a company or developer to place in the market their own virtual object, since nobody would be able to decode it without the suitable software.

2. Lack of Communications: Ideally for an object that is part of an IOT system in which various virtual and physic objects interact to automate tasks is that each object must communicate the actions it is able to execute to the other objects (Fig.1). Since there is no standard format way to get actions or services from a giving virtual object, it is very difficult to interact with another application.

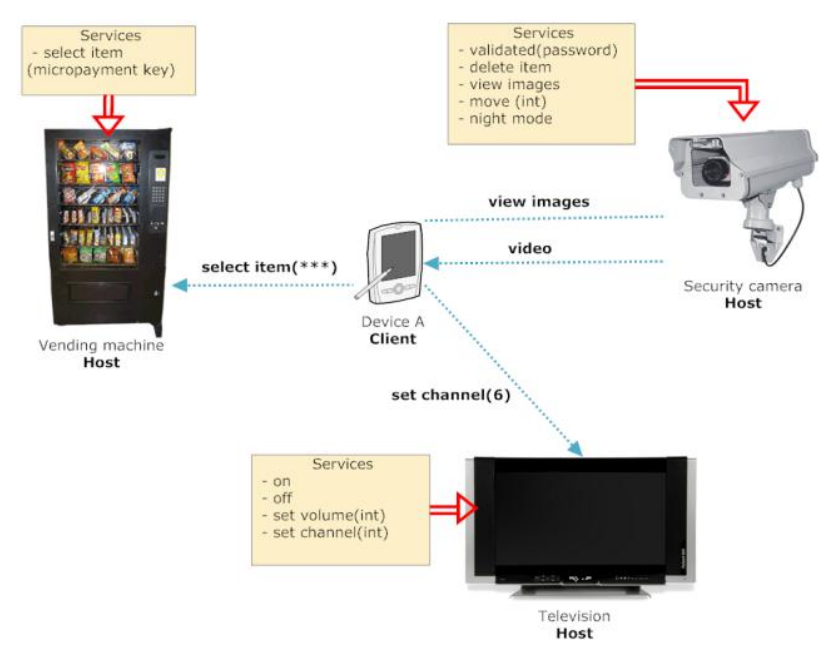

Fig. 1. Service Orchestration scenario.

This research provides a common structure for the construction of digital objects. Which gets all digital objects regardless of their complexity or business logic can be interpreted the same way by any electronic device that has the computing power required (embedded systems, computers, PDAs, mobile phones, etc). The proposal can eliminate the pre-configuration needs and specific software requirements for the manager of different digital objects $[1,2]$.

The proposed model encourages the integration and communication of digital objects, applications, devices and users. Establish a process similar to that followed for integration of physical elements in the network of the Internet of things, where digital objects should offer the possibility of other users or applications might discover them and get their catalog of actions.

The validity of the proposal has been illustrated with the development of several prototypes and specific test that evaluate the most important aspects of the proposal. 
International Journal of Artificial Intelligence and Interactive Multimedia, Vol. 1, $N^{o} 7$.

\section{REFERENCES}

[1] Pascual, J, Sanjuán, O., Cueva, J.M, Pelayo B.C., Álvarez, M. \& González, A. (2010). Modeling architecture for collaborative virtual objects based on services. Journal of Network and Computer Applications, v 34, n 5, (pp 1634-1647).

[2] Pascual, J, Sanjuán, O., Cueva, J.M, \& Pelayo B.C. (2011). Virtual objects on the Internet of things. International Journal of Interactive Multimedia and Artificial Intelligence, v 1, n 4, (pp 23-29).

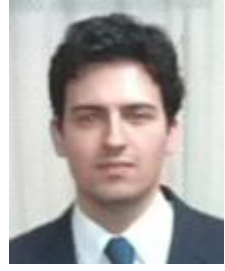

Pascual Espada, Jordan received a $\mathrm{PhD}$ in Computer Science from the University of Oviedo (Spain) in 2011. $\mathrm{He}$ is Research scientist at Computer Science Department of the University of Oviedo (Spain), also he assists on the development of cloud computing applications with Elasticbox. B.Sc. in Computer Science Engineering and a M.Sc. in Web Engineering from the University of Oviedo. His research interests include the Internet of Things, exploration of new applications and associated human computer interaction issues in ubiquitous computing and emerging technologies, particularly mobile and Web applications. He has been author of published papers in several journals and recognized international conferences and symposiums 